\title{
Identification of a Long-Lasting Form of Odor Adaptation that Depends on the Carbon Monoxide/cGMP Second- Messenger System
}

\author{
Frank Zufall and Trese Leinders-Zufall \\ Section of Neurobiology, Yale University School of Medicine, New Haven, Connecticut 06510
}

The diffusible messenger carbon monoxide (CO) has been proposed to mediate endogenous cyclic guanosine $3^{\prime}, 5^{\prime}-$ monophosphate (cGMP) formation and sensory adaptation in vertebrate olfactory receptor neurons (ORNs). We have identified and characterized a long-lasting form of odor response adaptation (LLA) that operates at the level of isolated salamander ORNs and does not require any interactions from other cells. Manifestations of LLA are seen in reduced amplitude and prolonged kinetics of the cAMP-mediated excitatory odor response and the generation of a persistent current component that lasts for several minutes and is attributable to cyclic nucleotide-gated (CNG) channel activation by cGMP. Because these effects can be mimicked by micromolar amounts of exogenous cGMP or CO, we applied various inhibitors of cGMP formation. LLA is abolished selectively by heme oxygenase inhibitors known to prevent $\mathrm{CO}$ release and cGMP formation in
ORNs, whereas odor excitation remains unaffected. In contrast, blockers of nitric oxide synthase are unable to eliminate LLA. Several controls rule out a contribution of nonspecific actions to the effects of $\mathrm{CO}$ inhibitors. The results indicate that endogenous CO/cGMP signals contribute to olfactory adaptation and underlie the control of gain and sensitivity of odor transduction. The findings offer a mechanism by which a single, brief odor stimulus can be translated into long-lasting intracellular changes that could play an important role in the perceptual adaptation to odors, and explain the longstanding puzzle that the olfactory CNG channels can be gated by both cAMP and cGMP.

Key words: olfactory receptor neuron; cyclic nucleotidegated channel; carbon monoxide; nitric oxide; cAMP; cGMP; salamander; sensory adaptation; heme oxygenase inhibitors
Carbon monoxide (CO) is a diffusible gas that, like nitric oxide (NO), activates soluble guanylyl cyclase (sGC) to stimulate cyclic guanosine 3',5'-monophosphate (cGMP) formation (Brüne and Ullrich, 1987; Furchgott and Jothianandan, 1991; Kharitonov et al., 1995). CO has been proposed to function as an endogenous messenger molecule in the nervous system (Marks et al., 1991; Maines, 1993; Verma et al., 1993; Ingi and Ronnett, 1995; Leinders-Zufall et al., 1995a; Ingi et al., 1996a) and to play roles in long-lasting changes of synaptic strength in hippocampus (Stevens and Wang, 1993; Zhuo et al., 1993), modulation of the odor sensitivity of olfactory neurons (Leinders-Zufall et al., 1996), regulation of carotid body sensory function (Prabhakar et al., 1995), and modulation of cerebellar neuronal activity (Nathanson et al., 1995).

Vertebrate olfactory receptor neurons (ORNs) are ideal for the dissection of $\mathrm{CO}$ action in modulating complex signaling cascades and addressing the functional relevance of $\mathrm{CO}$-mediated cGMP generation. ORNs contain high levels of the CO-producing enzyme heme oxygenase-2 (HO-2) (Verma et al., 1993; Ingi and Ronnett, 1995; Ingi et al., 1996b) but no nitric oxide synthase (NOS) activity (Kishimoto et al., 1993; Bredt and Snyder, 1994; Kulkarni et al., 1994; Roskams et al., 1994), which could confound

Received Dec. 2, 1996; revised Jan. 21, 1997; accepted Jan. 31, 1997.

This work was supported by Grant RO1-DC-02227 from the National Institute of Deafness and Other Communications Disorders to F.Z. We gratefully thank Gordon Shepherd, Charles Greer, and Paul Kingston for critically reading earlier versions of this manuscript and Steve Siegelbaum for a stimulating discussion.

Correspondence should be addressed to Dr. Frank Zufall, Section of Neurobiology, Yale University School of Medicine, 333 Cedar Street, New Haven, CT 06510.

Copyright (C) 1997 Society for Neuroscience $0270-6474 / 97 / 172703-10 \$ 05.00 / 0$ results. The primary response of ORNs to odor ligands is a rapid rise in cAMP, which directly opens $\mathrm{Ca}^{2+}$-permeable cyclic nucleotide-gated (CNG) ion channels (for review, see Lancet, 1986; Reed, 1992; Breer, 1993; Zufall et al., 1994). Interestingly, native olfactory CNG channels not only have been shown to be gated by cAMP, but also have retained a high sensitivity to cGMP (Nakamura and Gold, 1987; Zufall et al., 1991a; Frings et al., 1992); hence, changes in cGMP concentration can be monitored as ionic currents through CNG channels (Leinders-Zufall et al., 1995a, 1996).

Recently, several results have suggested that cGMP is part of the apparatus that mediates odor adaptation. (1) cGMP formation depends on the stimulus strength and only occurs with stronger odor stimuli (Breer et al., 1992; Verma et al., 1993; Kroner et al., 1996). (2) Its buildup is slow, reaches only low levels, and can outlast the cAMP response for minutes (Breer et al., 1992). (3) Exogenous cGMP produces an adaptation-like effect lasting for several minutes (Leinders-Zufall et al., 1996). (4) Only micromolar amounts of cGMP, known to occur in ORNs after stimulation with CO (Ingi and Ronnett, 1995; Leinders-Zufall et al., 1995a), are required for an adaptation effect. (5) The effect of cGMP can be mimicked by CO (Leinders-Zufall et al., 1996), which is produced in an odor-dependent manner (Verma et al., 1993).

To test a possible involvement of the CO/cGMP cascade in olfactory adaptation, we have searched for long-lasting forms of odor response adaptation. We have identified a form of olfactory adaptation that operates on the time scale of minutes and that we term LLA. Analysis of LLA reveals that its properties are indistinguishable from the effects of exogenous cGMP or CO. We then 
use pharmacological agents with established effects on $\mathrm{CO}$ generation and cGMP levels in ORNs to disrupt LLA.

\section{MATERIALS AND METHODS}

Dissociation and recording from ORNs. ORNs were freshly isolated from the nasal epithelium of adult land-phase tiger salamanders (Ambystoma tigrinum) by methods described in detail previously (Firestein et al., 1991b; Zufall et al., 1991a). No enzymes were used for the dissociation procedure. All of the cells used in this study were clearly identifiable as ORNs by their characteristic morphology, including a single thick dendrite ending in a knob-like swelling from which emanated half a dozen or more moving cilia. Macroscopic currents were recorded at $22-25^{\circ} \mathrm{C}$ under voltage clamp by applying the perforated patch technique with amphotericin B to gain electrical access to the interior of the cells (LeindersZufall et al., 1995a, 1996). A main advantage of this approach is to ensure the least possible disturbance of the internal milieu of the neurons and to prevent artificial $\mathrm{Ca}^{2+}$ buffering from influencing the results. We also found that amphotericin B recordings display very low levels in baseline noise (Leinders-Zufall et al., 1996), which is a prerequisite to detect reliably tonic shifts in the baseline current as low as $0.5 \mathrm{pA}$. Current recordings, command potential sequences, data acquisition, and on-line analysis were controlled by an EPC-9 patch-clamp amplifier, in combination with Pulse software (HEKA Electronic) and a Macintosh computer. Continuous currents (low resolution) were filtered at $300 \mathrm{~Hz}(-3$ $\mathrm{dB}, 8$-pole low-pass Bessel) and digitally sampled at $5 \mathrm{msec}$ per point. Single odor responses at expanded temporal resolution were sampled at $1 \mathrm{msec}$ per point. The indifferent electrode consisted of a $\mathrm{Ag}-\mathrm{AgCl}$ wire connected to the bath solution via an agar bridge. All data reported here have been corrected for junction potentials. The holding potential in all voltage-clamp experiments was $-60 \mathrm{mV}$. To measure the current-voltage $(I-V)$ relationship of the $\mathrm{CNG}$ conductance in intact cells, we applied voltage ramps (slope, $0.35 \mathrm{mV} / \mathrm{msec}$ ). Ramps were digitized at $100 \mu \mathrm{sec}$ per point.

All odor responses were elicited by brief, $100 \mathrm{msec}$ odor pulses. For sequential, repetitive stimulation, we used relatively long interstimulus intervals of $\geq 30 \mathrm{sec}$ to avoid early forms of adaptation (Kurahashi and Shibuya, 1990). Our basic paradigm to establish LLA was to elicit one conditioning pulse followed by a series of test pulses, all at fixed concentration. Before each experimental series, we gave a pulse of a relatively low cineole concentration (usually $10 \mu \mathrm{M}$ ). We found that cells that did not respond with measurable currents to the $10 \mu \mathrm{M}$ stimulus did not show LLA, even when responses could be elicited at higher cineole concentrations $(n=39)$. These cells were rejected from the current study but could be used for testing the effects of exogenous $\mathrm{CO}$ and 8-bromo-cGMP (8-Br-cGMP) (Leinders-Zufall et al., 1996). Conversely, except for one case, all cells that were sensitive to $10 \mu \mathrm{M}$ cineole pulses produced LLA $(n=33)$ and were used for further experiments as described here.

Solutions and chemicals. Cells were held in a laminar flow chamber and continuously superfused at a rate of $\sim 100 \mu \mathrm{l} / \mathrm{sec}$ with physiological Ringer's solution containing (in $\mathrm{mM}$ ): $115 \mathrm{NaCl}, 2.5 \mathrm{KCl}, 1.0 \mathrm{CaCl}_{2}, 1.5$ $\mathrm{MgCl}_{2}, 4.5 \mathrm{HEPES}$, and 4.5 Na-HEPES, pH 7.6, adjusted to $240 \mathrm{mOsm}$. For experiments with a lowered external $\mathrm{Ca}^{2+}$ concentration (Fig. 7), we used the following solution (in $\mathrm{mM}$ ): $105 \mathrm{NaCl}, 2.5 \mathrm{KCl}, 4.8 \mathrm{CaCl}_{2}, 1.5$ $\mathrm{MgCl}_{2}, 4.5 \mathrm{HEPES}, 4.5 \mathrm{Na}-\mathrm{HEPES}, 5$ EGTA, pH $7.6(\mathrm{NaOH})$. This solution results in a free $\mathrm{Ca}^{2+}$ concentration of $1 \mu \mathrm{M}$ as measured with a $\mathrm{Ca}^{2+}$-sensitive electrode. Because of the limit of precision of our $\mathrm{Ca}^{2+}$ selective electrode in this concentration range, $1 \mu \mathrm{M} \mathrm{Ca}^{2+}$ should be regarded as an upper limit for the accurate value. An estimate for this value was calculated from the stability constants, giving $0.6 \mu \mathrm{M}$ free $\mathrm{Ca}^{2+}$. The pipettes were filled with the following solution (in $\mathrm{mM}$ ): $17.7 \mathrm{KCl}$, 92.3 KOH, 82.3 methanesulfonic acid, 5.0 EGTA, 10 HEPES, pH 7.5 $(\mathrm{KOH})$, adjusted to $220 \mathrm{mOsm}$.

Odorant solutions containing cineole (Sigma, St. Louis, MO) were prepared in Ringer's solution with $<0.1 \%$ dimethyl sulfoxide (DMSO). Focal stimulation of olfactory cilia with well defined stimuli was obtained by pressure-ejecting the odorant solutions from multibarrel glass pipettes that were placed within $5-10 \mu \mathrm{m}$ from the cilia. Stimulus pipettes were located downstream from the cilia. Under these conditions, the solution switching time was $30-40 \mathrm{msec}$ as measured by the response to high $\mathrm{K}^{+}$ solutions. Odorant dose-response curves obtained with this method were in close agreement with cineole responses described previously in these cells (Firestein et al., 1993).

All metalloporphyrin solutions were made fresh each day. Zinc (II) protoporphyrin IX (ZnPP-9), zinc (II) deuteroporphyrin IX 2,4-bisglycol (ZnBG), and copper (II) protoporphyrin IX (CuPP-9) were obtained from LC Laboratories (Woburn, MA) and were initially dissolved in $100 \%$ DMSO to give $1 \mathrm{~mm}$ stock solutions. The agents were diluted to the final concentration immediately before use, sonicated, and applied by bath perfusion. Final concentrations of the metalloporphyrin solutions contained $<0.02 \%$ (vol/vol) DMSO. ORNs were preincubated for 20-30 $\mathrm{min}$ in these solutions before tests were carried out. Because metalloporphyrins are photoreactive (Vreman et al., 1993), solubilization, incubation, and recording were carried out at very low or zero ambient light to avoid breakdown and possible phototoxicity (Vreman et al., 1993; Meffert et al., 1994). The NO synthase blocker $N^{\mathrm{G}}$-nitro-L-arginine (LNOARG; Research Biochemicals International, Natick, MA) was dissolved in $0.1 \mathrm{~N} \mathrm{HCl}$ solution to give a $100 \mathrm{~mm}$ stock solution.

$\mathrm{CO}$ gas was obtained in research purity (Matheson, Gloucester, MA). We prepared CO stock solutions by bubbling the gas until saturation in distilled water, giving a concentration of $0.96 \mathrm{~mm}$ CO (solubility of CO: $2.691 \mathrm{mg} / 100 \mathrm{gm} \mathrm{H}_{2} \mathrm{O}$ at $23^{\circ} \mathrm{C}$ and $760 \mathrm{mmHg}$ ). This solution was immediately diluted to the desired concentration in Ringer's solution and injected directly into the recording chamber (Leinders-Zufall et al., 1995a, 1996). Other compounds, such as cadmium, W-7 ( $N$-(6-aminohexyl)-5-chloro-1-naphthalenesulfonamide), and LY83583 (6-(phenylamino)-5,8-quinolinedione; Research Biochemicals International) were delivered directly to individual cells via a multibarrel flow pipette apparatus. Unless otherwise stated, chemicals were obtained from Sigma.

Data analysis. All data analysis and calculations were performed using the Igor Pro software package (WaveMetrics) running on Macintosh computers. With this program, user-defined functions, in combination with an iterative Levenberg-Marquardt nonlinear least squares fitting routine, were applied to the data. If not otherwise stated, data are expressed as mean \pm SD and number of observations $(n)$. Statistical tests were performed using statistical software (SuperAnova version 1.1 and StatView version 4.0, Abacus Software, Berkeley, CA). Fisher's least significant difference (LSD) test was used as a post hoc comparison of the ANOVA.

\section{RESULTS}

\section{Long-lasting adaptation of the odor response of olfactory receptor cells}

Electrophysiological studies testing the effects of exogenous cGMP or CO on ORNs suggest that the following main steps are likely to occur after the formation of cGMP (Leinders-Zufall et al., 1995a, 1996): (1) generation of a persistent inward current with small amplitude lasting for several minutes and attributable to activation of the CNG channels by cGMP; (2) sustained $\mathrm{Ca}^{2+}$ influx through tonic $\mathrm{CNG}$ channel activation; and (3) reduction of the gain of the primary cAMP second-messenger cascade caused by the $\mathrm{Ca}^{2+}$ entry. Manifestations of this effect should be evident in a long-lasting decline of peak odor responses, a prolongation of the odor response kinetics, and characteristic changes of the odorant dose-response curve (Leinders-Zufall et al., 1996). To identify the effects of endogenous cGMP formation, we therefore searched for forms of olfactory adaptation with characteristics similar to the effects of exogenous CO/cGMP. Odor responses were elicited by repeated $100 \mathrm{msec}$ pulses of the single odor ligand cineole at various concentrations (Firestein et al., 1993; LeindersZufall et al., 1996), and currents were measured under voltage clamp by means of the perforated patch technique (LeindersZufall et al., 1996).

Under these experimental conditions, a time-dependent decrease in odor sensitivity resembling the effects of CO/cGMP occurs regularly after exposure to odor stimuli of a given strength. An example is illustrated in Figure $1 A$, in which four identical odor pulses at fixed concentration (10 $\mu \mathrm{M}$ cineole) produced transient inward currents with similar peak amplitudes, showing no signs of adaptation. An increase in the stimulus strength to $20 \mu \mathrm{M}$ cineole resulted in a larger initial response, an observation consistent with the dose-response behavior of these cells, but subsequent odor responses elicited by the same $20 \mu \mathrm{M}$ odor pulse progressively declined until reaching a new 

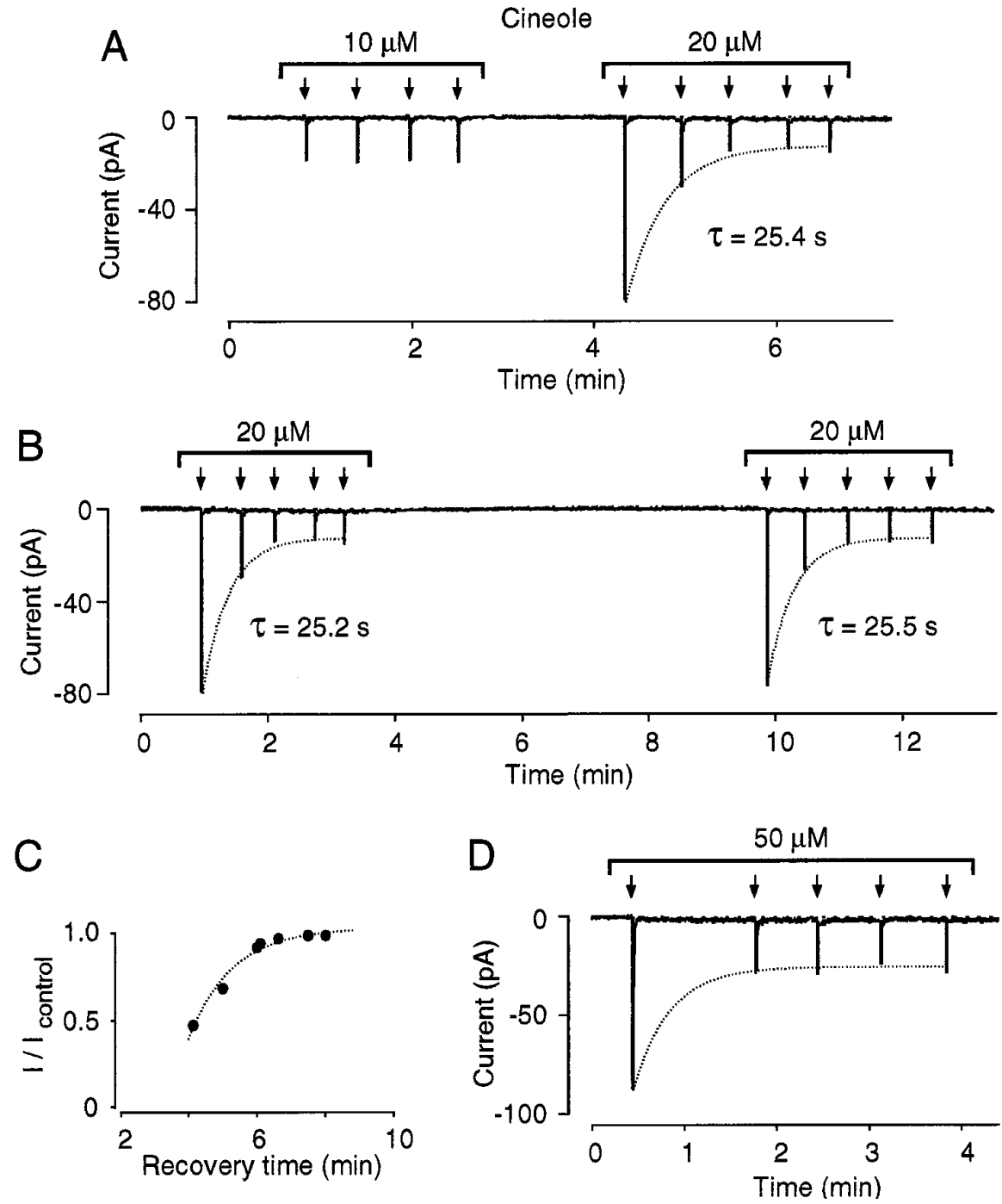

Figure 1. LLA of the odor response of isolated olfactory neurons. $A$, Response of an individual ORN to four repeated $100 \mathrm{msec}$ pulses of the odor ligand cineole plotted at low time resolution. Interstimulus interval was $\geq 30 \mathrm{sec}$. Arrows indicate odor stimuli. Cells were voltage-clamped by means of the perforated patch technique. Holding potential in all recordings was $-60 \mathrm{mV}$. Stimulation with $10 \mu \mathrm{M}$ cineole produces odor responses with peak amplitudes of $-18.6 \pm 0.6 \mathrm{pA}(n=4)$. An increase in stimulus strength to $20 \mu \mathrm{M}$ cineole results in a larger initial peak response $(-80.0 \mathrm{pA})$ followed by a time-dependent decline in odor responsiveness to $-14.1 \pm 0.6 \mathrm{pA}(n=3)$. The onset time course of LLA is fit with a single exponential function giving $\tau$ $=25.4 \mathrm{sec}$ (indicated by the dotted line). $B$, LLA recovers spontaneously after a $6.5 \mathrm{~min}$ period in odor-free solution. On further stimulation, readaptation proceeds with the same onset time course as in the control measurement. $C$, Plot of recovery time versus peak odor responses. Current amplitudes are plotted in normalized form, $I / I_{\text {control }}$, where $I_{\text {control }}$ is the incremental peak response to the first test pulse in the control series, and $I$ is the incremental peak response to the first test pulse in the second series. Same stimulation paradigm as in $B$. Data points are connected by eye. $D$, LLA does not depend directly on the repetition rate of the stimuli. When the interval between the first and second stimulus is increased to $1.3 \mathrm{~min}$, LLA proceeds with a similar time course as in control measurements. This is indicated by the dotted curve representing the average onset time course $(\tau=$ $24 \pm 4 \mathrm{sec}$ ) of LLA from 11 control cells stimulated with the pulse paradigm used in $B$. This experiment also demonstrates that a single $100 \mathrm{msec}$ stimulus of a given strength is sufficient to establish LLA. equilibrium at a 5.7-fold lower level (Fig. $1 A$ ). This adaptive effect is denoted here as long-lasting adaptation (LLA). LLA developed with a relatively slow onset time course, with a time constant of $\sim 25 \mathrm{sec}$ ( $n=11$ ) (Fig. $1 A$, dotted curve). Figure $1 B$ illustrates that LLA was fully reversible; after a $6.5 \mathrm{~min}$ period without odor stimulation, the initial odor response recovered spontaneously and, in response to further stimulation, readaptation proceeded with the same time course as in the control measurement (Fig. 1B). By using the same stimulation paradigm as in Figure $1 B$ and varying the interval (recovery time) during the two test series, we found that the time for full recovery from LLA was between 6 and 8 min (Fig. 1C). To distinguish LLA from a decreased responsiveness attributable to the repetition of the chemosensory stimuli, we increased the time interval between the first and second odor pulse $(n=5)$ (Fig. 1D). The results indicate that a single $100 \mathrm{msec}$ odor stimulus can be sufficient to fully establish LLA, and that LLA is not primarily caused by the repetition rate of the stimulus. In fact, it appears that LLA, once initiated, can proceed for several minutes with its own intrinsic time course in the absence of continuous odor stimulation.

LLA could not be elicited in every ORN responsive to cineole (cf. Leinders-Zufall et al., 1996). In an attempt to address whether a given cell would produce LLA, we found that the ability to initiate LLA was strongly correlated with the sensitivity of that cell for the odor ligand. Previous experiments have shown that each salamander ORN can respond to different odor molecules, but that each ORN responsive for a given odor ligand displays a characteristic range and $K_{1 / 2}$ value of the dose-response curve for that ligand (Firestein et al., 1993; Leinders-Zufall et al., 1996). The latter feature may reflect the specific tuning properties of odor receptor molecules for that stimulus (cf. Shepherd, 1994; Mori and Yoshihara, 1995). Here, we found that ORNs that displayed a heightened sensitivity to cineole or, in other words, those with the lowest $K_{1 / 2}$ values $\left[K_{1 / 2}=33.6 \pm 8.2 \mu \mathrm{M}(n=10)\right.$; range, 21.4-42.9 $\mu \mathrm{M}$ ] exhibited LLA, whereas ORNs with high $K_{1 / 2}$ values did not $\left[K_{1 / 2}=76.8 \pm 19.2 \mu \mathrm{M}(n=10)\right.$; range, $42-110$ $\mu \mathrm{M}$; Spearman rank correlation: $R_{\mathrm{s}}=-0.87 ; p<0.001 ; n=20$ ]. By contrast, there was no correlation between LLA and the maximal amplitude of odor currents in a given cell at saturating cineole concentrations $\left(R_{\mathrm{s}}=0.35 ; p=0.13 ; n=20\right)$. As a result of these observations, a simple test was performed with each ORN before an experimental series (see Materials and Methods) that enabled us to predict in all but one case whether LLA would occur.

\section{Long-lasting adaptation is indistinguishable from the effects of CGMP or CO}

The characteristics of LLA as seen in Figure 1 are strikingly similar to the adaptation effect produced by exogenous cGMP or 
A

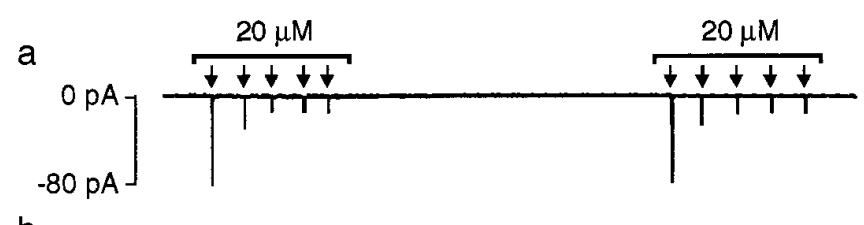

b

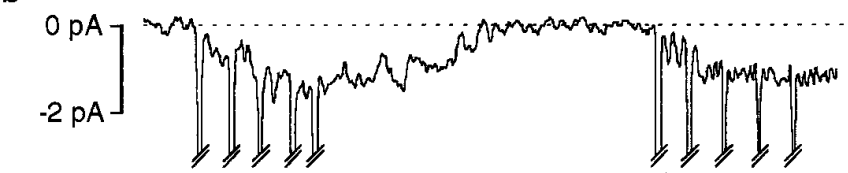

C

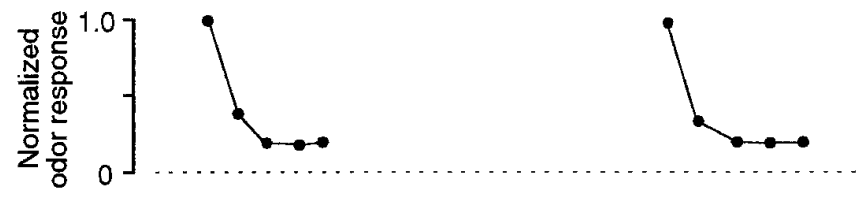

d

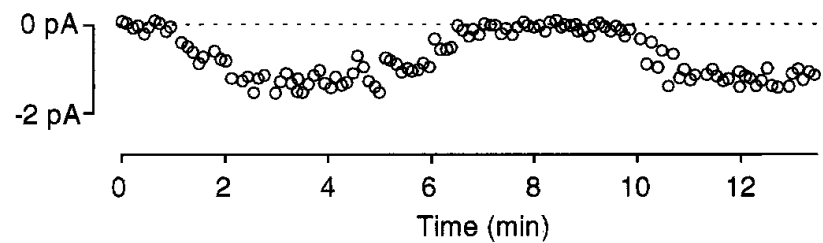

B
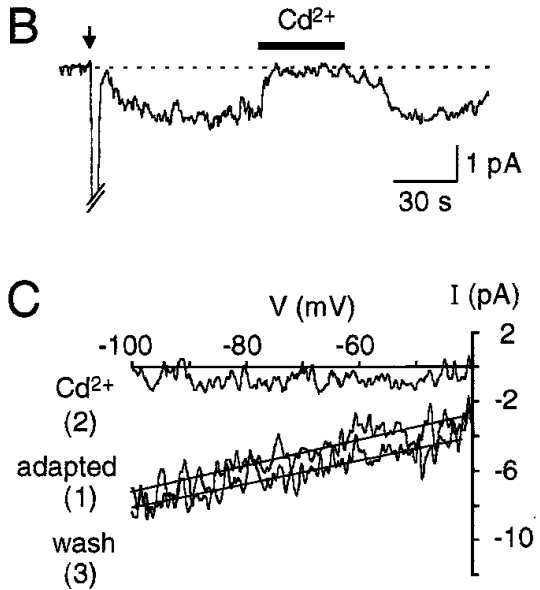

(3)

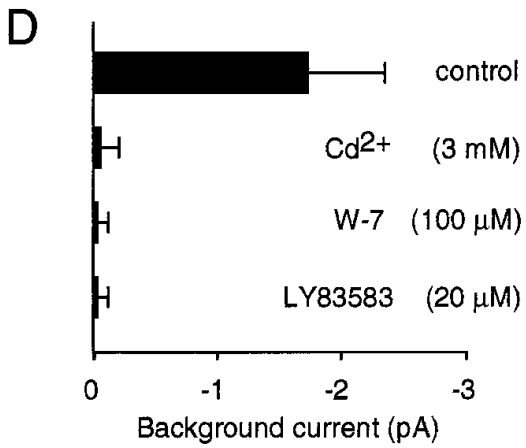

Figure 2. LLA is associated with the generation of a persistent background current. $A$, Temporal relation between persistent inward current and diminished responsiveness of primary odor currents. Same experiment as shown in Figure $1 B$. Aa, To facilitate viewing of the whole experiment, odor responses are replotted at low-amplitude resolution. $A b$, With higher resolution, the generation of small sustained inward currents of approximately -1.3 pA becomes evident. These background currents are activated on odor stimulation after the first test pulse and recover spontaneously back to baseline 3-4 min after the last odor pulse. Ac, To quantify the time-dependent reduction in odor responsiveness, peak odor responses are plotted in normalized form with respect to the incremental peak amplitude of the first odor response of the experiment. $A d$, Time course of the background current. Each plotted data point represents the mean of 651 data points. Data points representing transient odor currents are omitted from the plot. $B$, A single 100 msec pulse of cineole $(80 \mu \mathrm{M})$ (arrow) results in the activation of a transient odor current followed by the persistent background current. Rapid addition of $\mathrm{Cd}^{2+}(3 \mathrm{mM})$ blocked the persistent current. This effect can be reversed on washout of $\mathrm{Cd}^{2+} . C, I-V$ analysis of odor-stimulated background current (from voltage ramps; see Materials and Methods) at three different conditions: (1) after induction of the background current; (2) in the presence of 3 $\mathrm{mM} \mathrm{Cd}{ }^{2+}$ in the bath solution; and (3) after washout of $\mathrm{Cd}^{2+}$. Ramp currents taken under control conditions have been subtracted. $D$, Effect of the CNG channel inhibitors $\mathrm{Cd}^{2+}, \mathrm{W}-7$, and LY83583 on the amplitude of odor-stimulated background currents yielding the following data: $-1.7 \pm 0.6 \mathrm{pA}(n=$ 10) $($ control $) ;-0.05 \pm 0.15 \mathrm{pA}(n=3)\left(3 \mathrm{mM} \mathrm{C} d^{2+}\right) ;-0.02 \pm 0.07 \mathrm{pA}(n=3)(100 \mu \mathrm{M} W-7)$; and $0.03 \pm 0.08 \mathrm{pA}(n=3)(20 \mu \mathrm{M} L Y 83583)$. Experiments were performed as in $B$.

CO (Leinders-Zufall et al., 1996). More detailed analysis of LLA provides additional evidence for this notion. As with the effects of $\mathrm{CO} / \mathrm{cGMP}$, LLA is associated with the generation of a persistent background current. Figure $2 A$ illustrates that stimulation of an ORN with a single odor ligand resulted in the activation of two different types of ionic currents: large transient inward currents (termed primary odor response) and relatively small, sustained inward currents. Examination of the current traces at higher resolution (Fig. $2 A b, A d$ ) revealed the time course and temporal relation of the sustained currents with respect to the transient odor currents and the development of LLA (Fig. $2 A a, A c)$. Small net inward currents, reaching an amplitude of approximately -2 $\mathrm{pA}$ on average, were generated upon odor stimulation and recovered back to baseline $\sim 3-4$ min after the last odor stimulus of a test series. This effect was repeatable upon stimulation in a second test series (Fig. $2 A b, A d$ ) and was seen in all cells that produced LLA $(n=33)$. These background currents developed immediately after the first primary odor current of a test series. Hence, activation of the background current is secondary to the cAMP- mediated odor response, but precedes the decline of the primary odor responses, suggesting that the tonic background current may underlie the reduced odor sensitivity observed here (LeindersZufall et al., 1996). Like odor-induced cGMP formation, activation (induction) of the background currents was dependent on the stimulus strength. Low odor concentrations insufficient to elicit LLA failed to induce background currents $(n=21)$. Conversely, all cells that responded to a specific stimulus strength with LLA also generated a background current at the same stimulus intensity $(n=33)$. This provides further evidence that the background currents were causal to LLA.

Several ionic and pharmacological tests were carried out to examine whether the background currents were mediated by CNG channel activation. Figure $2 B$ illustrates an experiment in which a single $100 \mathrm{msec}$ pulse of cineole (arrow) resulted in the activation of a transient odor current followed by the persistent background current. Rapid addition of $\mathrm{Cd}^{2+}(3 \mathrm{~mm})$ blocked the persistent current. This effect was fully reversible upon washout of $\mathrm{Cd}^{2+}$, consistent with previous results showing that millimolar 
Table 1. Evidence that odor-induced background currents are mediated by CNG channel activation

\begin{tabular}{|c|c|c|}
\hline & $\begin{array}{l}\text { Odor-induced } \\
\text { background } \\
\text { current }\end{array}$ & $\begin{array}{l}\text { CNG channel } \\
\text { current } \\
\text { activated by } \\
\text { 8-Br-cGMP }\end{array}$ \\
\hline $\begin{array}{l}\text { Amplitude }(\mathrm{pA}) \\
\quad\left(1 \mathrm{~mm} \text { external } \mathrm{Ca}^{2+}\right)\end{array}$ & $\begin{array}{l}-1.7 \pm 0.6 \\
(n=10)\end{array}$ & $\begin{array}{l}-1.2 \pm 0.5 \\
(n=3)\end{array}$ \\
\hline $\begin{array}{l}\text { Reversal potential }(\mathrm{mV}) \\
\left(1 \mathrm{~mm} \text { external } \mathrm{Ca}^{2+}\right)\end{array}$ & $\begin{array}{l}-27.4 \pm 9.5 \\
(n=10)\end{array}$ & $\begin{array}{l}-29.0 \pm 3.6 \\
(n=3)\end{array}$ \\
\hline $\begin{array}{l}\text { Amplitude }(\mathrm{pA}) \\
\quad\left(\text { external } \mathrm{Ca}^{2+} \text { reduced }\right)\end{array}$ & $\begin{array}{l}-19.5 \pm 8.4 \\
(n=3)\end{array}$ & $\begin{array}{l}-15.0 \pm 4.5 \\
(n=3)\end{array}$ \\
\hline $\begin{array}{l}\text { Reversal potential }(\mathrm{mV}) \\
\quad\left(\text { external } \mathrm{Ca}^{2+} \text { reduced }\right)\end{array}$ & $\begin{array}{l}+7.6 \pm 12.1 \\
(n=3)\end{array}$ & $\begin{array}{l}-3.8 \pm 8.1 \\
(n=3)\end{array}$ \\
\hline $\mathrm{Cd}^{2+}(3 \mathrm{~mm})$ & Complete block & Complete block \\
\hline LY83583 $(20 \mu \mathrm{M})$ & Complete block & Complete block \\
\hline W-7 (100 $\mu \mathrm{M})$ & Complete block & Complete block \\
\hline
\end{tabular}

Currents through CNG channels were measured with the use of the perforated patch-clamp technique as described previously (Leinders-Zufall et al., 1995a, 1996) A concentration of $1 \mu \mathrm{M} 8$-Br-cGMP was used in these experiments because this cGMP level can be produced by physiological concentrations of CO (Leinders-Zufall et al., 1995a). For the analysis of the effect of low external $\mathrm{Ca}^{2+}(0.6 \mu \mathrm{M})$ on established odor-induced background currents, cells were first exposed to normal 1 mM external $\mathrm{Ca}^{2+}$ and stimulated with an odor pulse as shown in Figure $2 B$. After the background current was fully activated, rapid switching to low $\mathrm{Ca}^{2+}$ solution was performed. The shift in reversal potential under low $\mathrm{Ca}^{2+}$ presumably reflects a contribution of secondary, $\mathrm{Ca}^{2+}$-dependent conductances to the net inward currents observed here.

doses of $\mathrm{Cd}^{2+}$ block the ionic pore of CNG channels but not the underlying second-messenger cascade (Zufall and Firestein, 1993; Ahmad et al., 1994; Leinders-Zufall et al., 1995a,b). $I-V$ analysis (Fig. $2 C$ ) revealed that the background currents were caused by a conductance increase ranging from 38 to $266 \mathrm{pS}(n=10)$. Like the persistent currents through $\mathrm{CNG}$ channels activated by exogenous CO/cGMP (Leinders-Zufall et al., 1996) (Table 1), odor-induced background currents could be abolished reversibly by other CNG channel inhibitors besides $\mathrm{Cd}^{2+}$, such as the calmodulin inhibitor W-7 (100 $\mu \mathrm{M})$ (Fig. 2D) (Kleene, 1994; Leinders-Zufall et al., 1995a). Furthermore, established background currents were inhibited by LY83583 (20 $\mu \mathrm{M})$ (Fig. 2D), which is known as a guanylyl cyclase inhibitor (Leinders-Zufall et al., 1995a) but acts also as an open channel blocker of the CNG channels themselves, with a $K_{1 / 2}$ of $1.4 \mu \mathrm{M}$ (Leinders-Zufall and Zufall, 1995). A detailed comparison of the properties of currents through CNG channels induced by exogenous 8 -Br-cGMP with the tonic odorstimulated background currents demonstrates that both had closely similar properties (see Table 1). Collectively, these results indicate that the persistent currents, like the large transient odor responses, were caused primarily by the activation of CNG channels.

Figure 3 illustrates another characteristic feature of LLA shared with the effects of exogenous CO/cGMP on odor responses, i.e., a specific alteration of the odor response kinetics (Leinders-Zufall et al., 1996). A plot of the odor responses at higher temporal resolution, both as original currents (Fig. $3 A$ ) and in normalized form (Fig. $3 B$ ), reveals that both the rising and the decaying kinetics of the currents were markedly prolonged after inducing LLA. The time-to-peak increased from $630 \pm 130 \mathrm{msec}$ $(n=10)$ under control conditions to $790 \pm 150 \mathrm{msec}(n=10)$ during LLA. The decay time course was fitted with single exponential functions giving time constants of $\tau=510 \pm 130 \mathrm{msec}$ $(n=10)$ (control) and $\tau=630 \pm 250 \mathrm{msec}(n=10)$ (LLA). Thus,
LLA reduced the amplitude and increased the time-to-peak and recovery time of the odor response. In addition to these effects, it is evident from Figure 3 that LLA also markedly decreased the initial slope of the rising phase of the response. These results thus constitute a powerful set of constraints for the future identification of the downstream molecular sites mediating long-lasting odor adaptation (cf. Detwiler and Gray-Keller, 1996).

Collectively, the data of Figures 1-3 demonstrate that LLA is virtually indistinguishable from the effects caused by low micromolar amounts of CO or cGMP on ORNs. These results therefore suggest a model in which LLA is induced by the endogenous formation of cGMP.

\section{Inhibition of the CO/cGMP pathway eliminates long- lasting adaptation}

To test the hypothesis that LLA is caused by endogenous cGMP production, we analyzed the effects of pharmacological inhibitors of the cGMP second-messenger system. Figure $4 A$ schematizes the proposed role of cGMP in odor transduction (Leinders-Zufall et al., 1996). According to this model, excitation and long-lasting adaptation are attributable to the activation of distinct, parallel second-messenger pathways, i.e., the cAMP cascade leading to transient activation of the CNG channels and the cGMP system resulting in persistent $\mathrm{CNG}$ channel activity. If this model is correct, then selective blockade of the cGMP pathway should prevent induction of the sustained background currents, as well as LLA, but should not affect the primary excitation process.

To inhibit cGMP production, we attempted to block the COgenerating enzyme HO-2. Previous work has shown that ORNs contain high levels of HO-2 but lack NOS activity; therefore, it has been proposed that $\mathrm{CO}$ may function as an endogenous activator of olfactory sGC (Verma et al., 1993; Ingi and Ronnett, 1995). In cultured ORNs, release of CO and cGMP formation can be inhibited effectively by ZnPP-9 (Ingi and Ronnett, 1995), a potent inhibitor of heme oxygenase activity (Maines, 1981). We therefore preincubated the ORNs in ZnPP-9 (100 nM). Consistent with the proposed model (Fig. $4 A$ ), this treatment abolished LLA $(n=4)$, even when very high odor concentrations were applied (300 $\mu \mathrm{M}$ cineole) and odor currents were monitored over long recording times (up to $15 \mathrm{~min}$ ) (Fig. $4 C$ ). Furthermore, induction of the persistent background current was suppressed in the presence of ZnPP-9 $(n=4)$ (Fig. $5 A)$, giving additional support to the notion that it results from activation of CNG channels by cGMP signals. In contrast, the excitatory cAMP-mediated response was not altered by ZnPP-9 (see Fig. 4C, insert), providing an important internal control concerning the pathway selectivity of the treatment.

Because of concerns about the specificity of ZnPP-9 as an inhibitor of heme oxygenase function (Meffert et al., 1994) a series of control experiments was carried out. First, we tested another inhibitor of HO-2, ZnBG (300 nM) (Vreman et al., 1991), and found that it also abolished LLA and left the excitation process unchanged $(n=3)$ (Fig. $4 D)$. The slightly smaller potency of ZnBG compared with ZnPP-9 resembles the potencies of these two agents on cGMP production in cultured ORNs (Ingi and Ronnett, 1995). To assess potential nonspecific effects of the metalloporphyrin inhibitors, we examined CuPP-9 (100 nM), which does not inhibit HO-2 (Yoshinaga et al., 1982; Prabhakar et al., 1995). CuPP-9 at a dose comparable to ZnPP-9 failed to prevent LLA $(n=3)$ (Fig. $4 E)$. More importantly, a specific inhibitor of NOS, L-NOARG $(100 \mu \mathrm{M})$, did not eliminate LLA $(n=3)$ (Fig. $4 F)$ even when used at 1000 -fold higher concentra- 
A

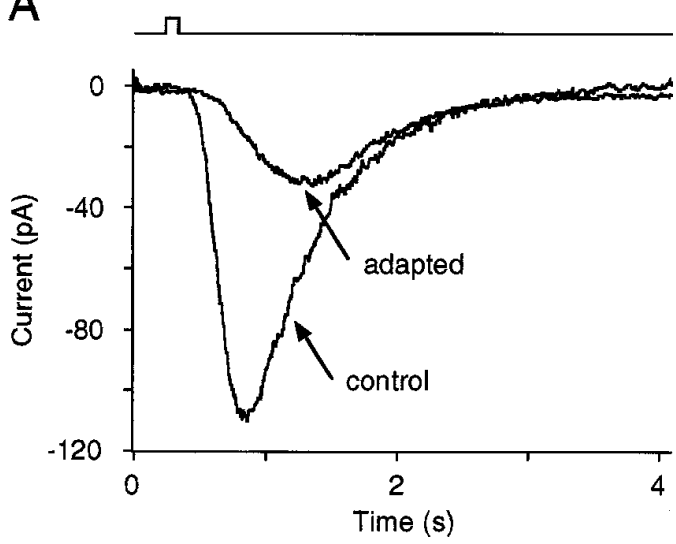

B

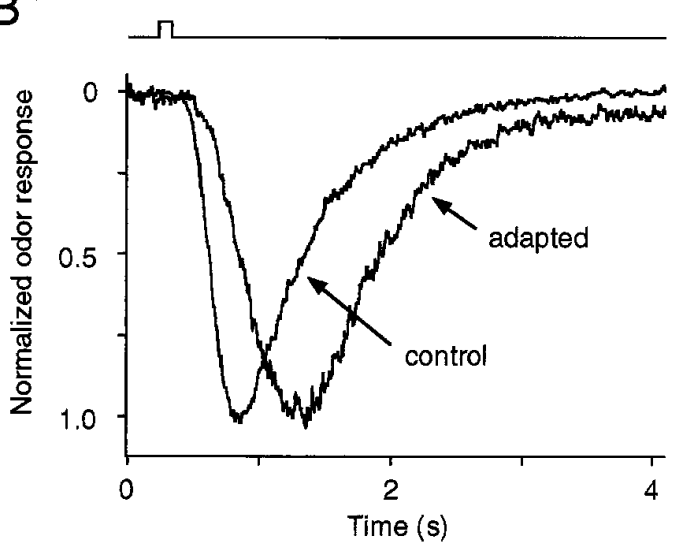

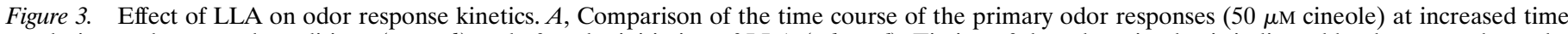

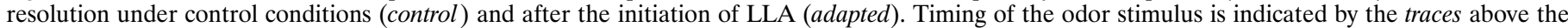

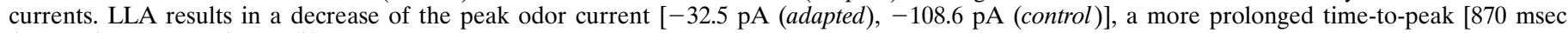

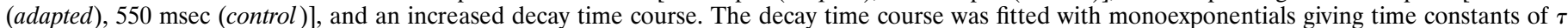

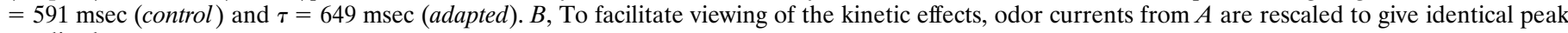
amplitudes.

tions than ZnPP-9. The same result was obtained with $N^{\mathrm{G}}$ monomethyl-L-arginine (L-NMMA; $100 \mu \mathrm{M})$, another inhibitor of NOS $(n=3)$ (not shown). The result that NOS inhibitors are ineffective in preventing LLA strongly argues against a role of NO in this process and is consistent with reports that known isoforms of NOS are absent from adult vertebrate ORNs (Kishimoto et al., 1993; Bredt and Snyder, 1994; Kulkarni et al., 1994; Roskams et al., 1994) and that NOS inhibitors fail to prevent CO release and cGMP formation in these cells (Verma et al., 1993; Ingi and Ronnett, 1995).

Inhibitors of the CO/cGMP system not only abolished LLA, but also prevented induction of the secondary odor-stimulated background currents. Figure 5 illustrates that the pharmacological profile of the background currents was identical to that obtained for LLA in Figure 4. All agents that abolished LLA, such as ZnPP-9 and ZnBG, also suppressed activation of the background currents. Conversely, compounds that were ineffective in eliminating LLA, such as CuPP-9, L-NOARG, and L-NMMA, failed to suppress activation of the background current (Fig. 5). These results are fully consistent with the predictions from the model outlined in Figure $4 A$.

\section{Long-lasting adaptation can be restored in the presence of heme oxygenase inhibitors}

$\mathrm{ZnPP}-9$ is believed to inhibit heme oxygenase by acting as a pseudosubstrate for heme (iron protoporphyrin IX) (Maines, 1981; Vreman et al., 1989). Previous reports have shown that ZnPP-9 sometimes can also alter the activity of other hemecontaining enzymes besides heme oxygenase such as sGC (Ignarro et al., 1984; Luo and Vincent, 1994). Further controls were performed to assess the possibility that ZnPP-9 blocked the cGMP pathway downstream from $\mathrm{HO}-2$. In Figure $6 A$, whole-cell currents through $\mathrm{CNG}$ channels resulting from stimulation of $\mathrm{sGC}$ by known concentrations of exogenous CO (Leinders-Zufall et al., 1995a) were generated in the presence and absence of ZnPP-9 (250 nM). This experiment was performed using a CO concentration $(2.4 \mu \mathrm{M})$ close to the $K_{1 / 2}$ value of the CO dose-response curve (Leinders-Zufall et al., 1995a). No significant difference was found between the ability of $\mathrm{CO}$ to stimulate $\mathrm{CNG}$ channel activation in the presence or absence of ZnPP-9 (Student's $t$ test; $p=0.62$ ) (Fig. 6A). Therefore, we conclude that ZnPP-9, at least in the low concentrations used in this study, had no significant effect on olfactory sGC, which is consistent with previous biochemical work (Ingi and Ronnett, 1995). Furthermore, other downstream components of the cGMP pathway were not altered significantly by ZnPP-9 (Fig. 6B). In the presence of ZnPP-9, LLA could be restored in a concentration-dependent manner by adding the membrane-permeant cGMP analog 8-Br-cGMP (Fig. 6B) $(n=3)$. A similar result was obtained by adding exogenous $\mathrm{CO}(1$ $\mu \mathrm{M}$ ) (not shown). These data demonstrate that the molecular components downstream from HO-2 needed to produce LLA were functionally intact in the presence of ZnPP-9. Collectively, the results provide strong evidence to conclude that $\mathrm{ZnPP}-9$ acted at the level of HO-2 in these experiments and that LLA was caused by the endogenous release of $\mathrm{CO}$ leading to stimulation of sGC and subsequent cGMP formation.

\section{DISCUSSION}

Although much progress has been made in identifying the molecular components mediating odor detection and excitation in the vertebrate olfactory system in past years, the mechanisms underlying olfactory adaptation remained elusive. Here we have identified a form of odor adaptation that operates at the level of individual ORNs and does not require any cooperative interactions from other cells. A single brief exposure $(100 \mathrm{msec})$ of a given amount of the odor ligand cineole to isolated ORNs produced a progressive, reversible, and relatively long-lasting decline of the response to that stimulus. This phenomenon is denoted LLA because complete recovery from its effect occurred after 6-8 min, sharply distinguishing it from early forms of olfactory adaptation (Getchell and Shepherd, 1978; Kurahashi and Shibuya, 1990; Zufall et al., 1991b). It seems likely that LLA is related to forms of long-lasting odor adaptation described previously at the cellular and systems level in humans (Ekman et al., 1967; Murphy, 1987), amphibia (Baylin and Moulton, 1979; Getchell, 1986), insects (Zack-Strausfeld and Kaissling, 1986; Marion-Poll and Tobin, 1992), crustaceans (Voigt and Atema, 1990), and nematodes (Colbert and Bargmann, 1995). 
A

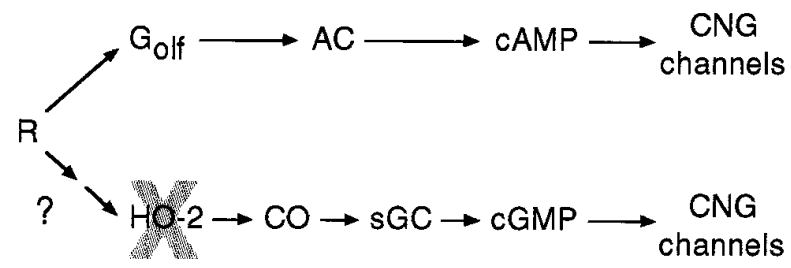

LONG-LASTING ADAPTATION

C

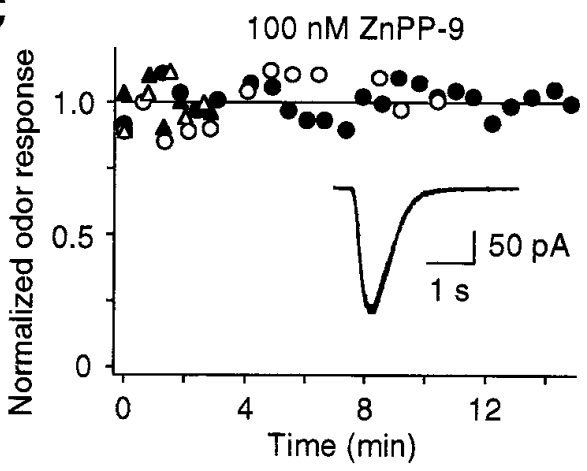

$E$

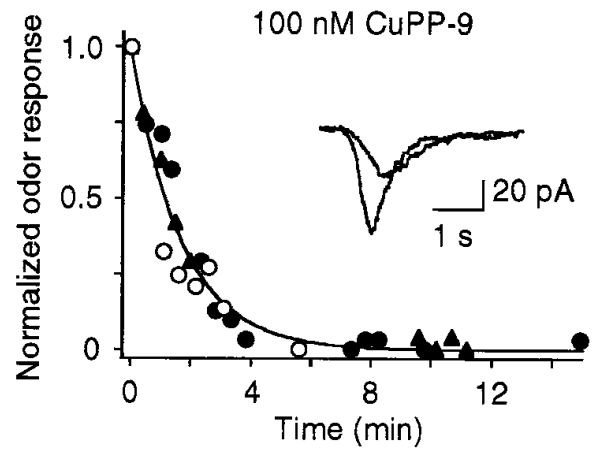

B

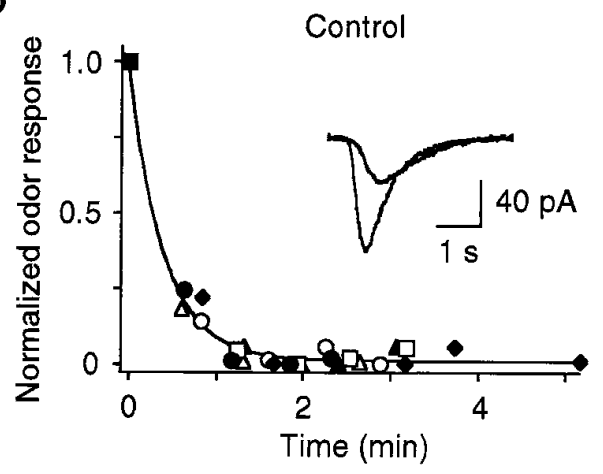

$\mathrm{D}$

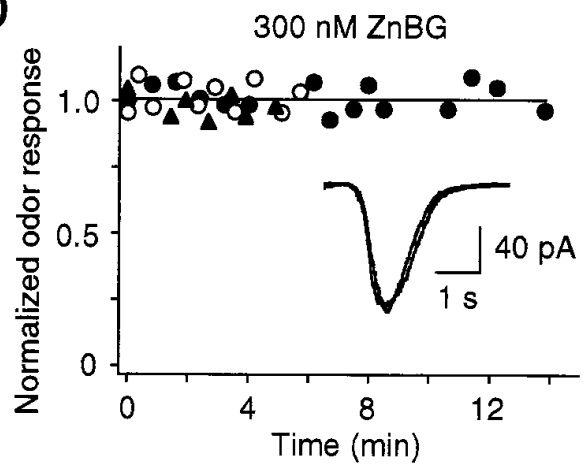

F

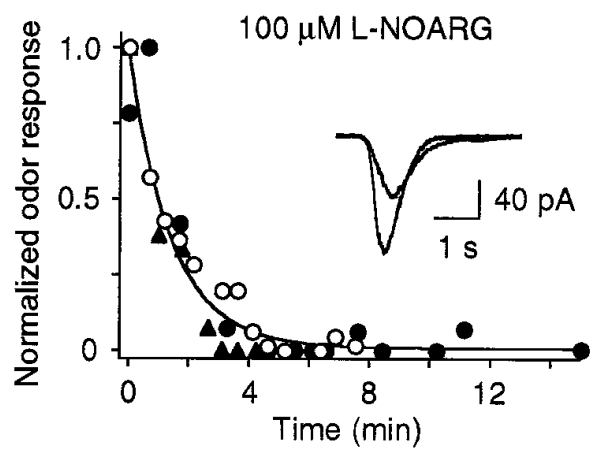

Figure 4. LLA is abolished by pharmacological blockade of the CO/cGMP system. $A$, Model for the proposed role of the cGMP second-messenger system in olfactory transduction, based on previous results (Leinders-Zufall et al., 1996). According to this model, the processes leading to excitation and long-lasting adaptation are attributable to the activation of distinct, parallel second-messenger pathways, i.e., the cAMP cascade leading to transient activation of the $\mathrm{CNG}$ channels and excitation, and the cGMP system resulting in persistent CNG channel activity and long-lasting adaptation. $R$, Odor receptor; $G_{o l f}$, stimulatory $\mathrm{G}_{\alpha \mathrm{s}}$-like G-protein; $A C$, adenylyl cyclase type III. $B$, Plot of the onset time course of LLA under control conditions. Data are from six cells (shown with different symbols). Cells are stimulated with $300 \mu \mathrm{M}$ cineole. Odor responses of a given cell are normalized to $\left(I-I_{\mathrm{LLA}}\right) /\left(I_{\text {control }}\right.$ $\left.-I_{\mathrm{LLA}}\right)$, so that the incremental peak response under control conditions $\left(I_{\text {control }}\right)$ is set to the value 1 , and the mean equilibrium peak response after producing LLA $\left(I_{\mathrm{LLA}}\right)$ is given the value 0 . Continuous line is a best fit of the data with a single exponential function giving a time constant $\tau=24$ sec. Insets are representative waveforms of transient odor-induced currents taken before LLA (large response) and after LLA was established (small response). $C$, Effect of ZnPP-9 (100 nM, $n=4)$ on LLA demonstrating that LLA is abolished after ZnPP-9 treatment in all tested cells. Solid line was computed by regression analysis. Insets demonstrate that the characteristic properties of the cAMP-mediated response remain unchanged during ZnPP-9 treatment and that there is no response decrement over time (second response was taken $12 \mathrm{~min}$ after the first odor response). $D$, Lack of LLA after ZnBG treatment (300 nM, $n=3)$. Same analysis as in $C . E$, CuPP-9 $(100 \mathrm{nM})$ is unable to abolish LLA $(n=3)$. There is, however, a slight increase in the onset time constant of LLA $(\tau=98 \mathrm{sec})$ during CuPP-9 treatment compared with control measurements of $B$, presumably reflecting the nonspecific effects of CuPP-9. The characteristic waveform of odor currents before and after producing LLA is unaltered by CuPP-9. F, L-NOARG (100 $\mu$ M) is unable to prevent LLA $(n=3)$, but slightly increases the onset time constant of LLA $(\tau=82 \mathrm{sec})$ without altering the characteristic waveform of odor currents before and after establishing LLA. 


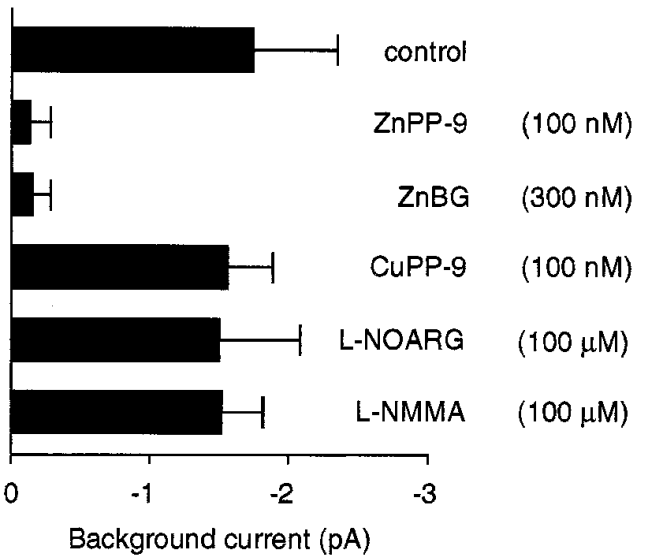

Figure 5. Effect of pharmacological inhibitors of the cGMP secondmessenger system on activation (induction) of odor-stimulated background current. The following data are obtained: $-1.7 \pm 0.6 \mathrm{pA}$ (control, $n=10$ ); $-0.12 \pm 0.16 \mathrm{pA}(100 \mathrm{~nm} Z n P P-9, n=4) ;-0.14 \pm 0.14 \mathrm{pA}(300 \mathrm{~nm} \mathrm{ZnBG}$, $n=3) ;-1.54 \pm 0.34 \mathrm{pA}(100 \mathrm{~nm}$ CuPP-9, $n=3),-1.48 \pm 0.59 \mathrm{pA}(100 \mu \mathrm{M}$ $L-N O A R G, n=3) ;-1.50 \pm 0.31 \mathrm{pA}(100 \mu \mathrm{M} L-N M M A, n=3)$.

\section{Alternative second messengers mediate distinct olfactory functions}

The most striking result of the present study is that LLA can be uncoupled from excitation and completely abolished by exposure of the cells to the metalloporphyrin inhibitors ZnPP-9 and $\mathrm{ZnBG}$, both at nanomolar concentrations. This treatment results in a highly specific action, because the properties of the cAMPmediated transduction cascade remain unaltered by these agents, and a structurally nearly identical porphyrin analog, CuPP-9, is ineffective in preventing LLA. Thus, the results demonstrate that odorant excitation and LLA are attributable to the activation of distinct biochemical processes. In light of the current interest for the role of multiple second-messenger systems in ORNs (Breer, 1993; Dionne, 1994; Zhainazarov and Ache, 1995; Brunet et al., 1996; Restrepo et al., 1996), our study provides some of the first clear evidence that different functions of olfactory transduction, such as excitation and LLA, are caused by the activity of different, parallel second-messenger cascades. This result is in close agreement with conclusions drawn from a recent study in Caenorhabditis elegans, in which the mutation of specific genes affected the adaptation process but did not diminish the ability of unadapted animals to respond to odors (Colbert and Bargmann, 1995). Hence, it appears that common strategies to produce long-term forms of odor adaptation could have evolved in phylogenetically diverse nematodes and amphibia.

\section{A role for cGMP in odor adaptation}

Our results strongly support the proposal that cGMP contributes to olfactory adaptation by modulating the signaling properties of ORNs, thereby controlling the gain and sensitivity of the excitatory cAMP cascade (Breer and Shepherd, 1993; Kroner et al., 1996; Leinders-Zufall et al., 1996). Detailed analysis of LLA reveals that its temporal behavior and dependence on stimulus strength are fully compatible with the properties of odorstimulated cGMP generation. More importantly, LLA is indistinguishable from the adaptation effect produced by exogenous cGMP (Leinders-Zufall et al., 1996).

How might odor-stimulated cGMP signals be generated? Given that adult vertebrate ORNs contain some of the highest levels of HO-2, whereas NO synthase is absent from these cells (see intro-
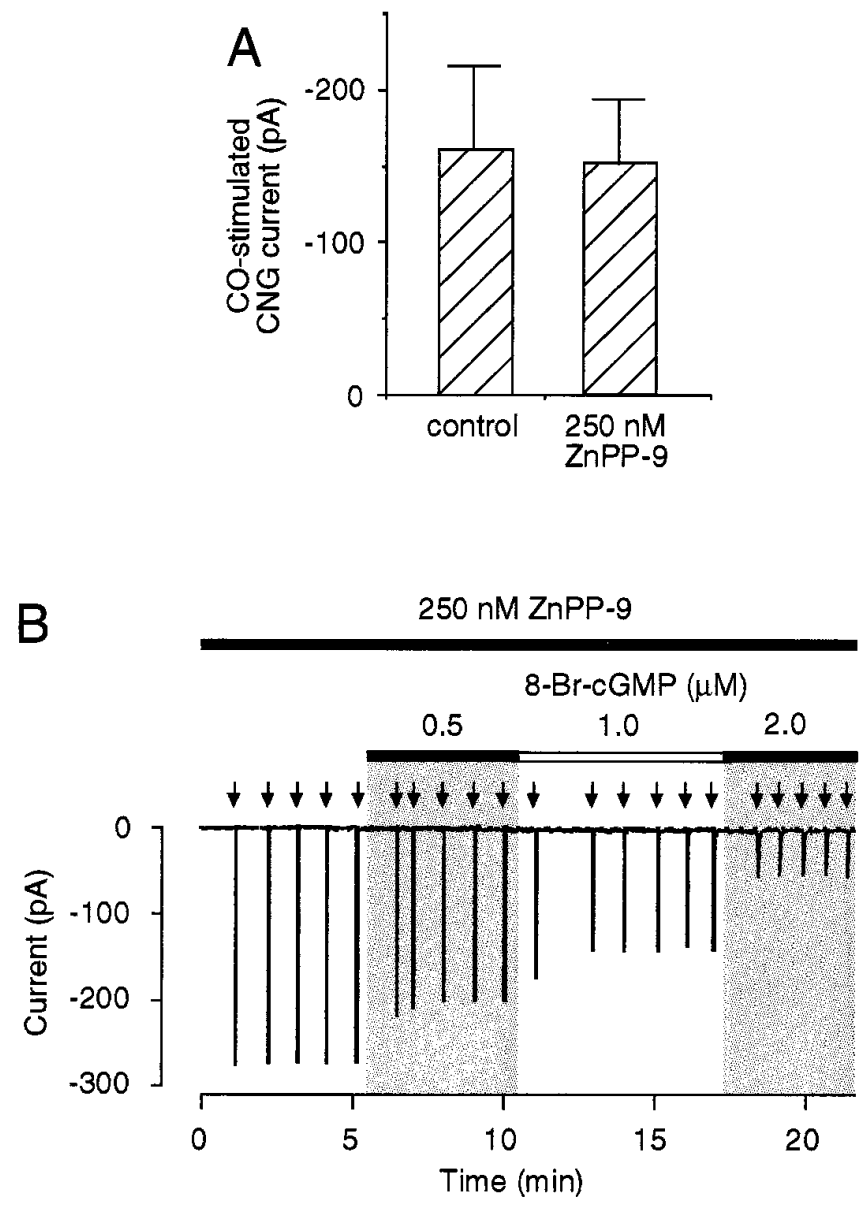

Figure 6. A, Analysis of currents through $\mathrm{CNG}$ channels stimulated by known concentrations of exogenous $\mathrm{CO}(2.4 \mu \mathrm{M})$ in the absence and presence of ZnPP-9 (250 nM). This experiment was performed under whole-cell recording conditions as described previously (Leinders-Zufall et al., 1995a). Control, $-161.3 \pm 54.6 \mathrm{pA}(n=6)$; ZnPP-9 $(250 \mathrm{nM})$, $-151.9 \pm 41.8 \mathrm{pA}(n=5)$. Note that there is no significant difference between the two results (Student's $t$ test; $p=0.62$ ), indicating that ZnPP-9 has no significant effect on olfactory sGC activation at concentrations used here. $B$, In the presence of ZnPP-9 (250 nM), LLA can be restored in a concentration-dependent manner by supplying various concentrations of the membrane-permeant cGMP analog 8-Br-cGMP. Odor responses are elicited by identical pulses of $300 \mu \mathrm{M}$ cineole (arrows).

ductory remarks), and that $\mathrm{HO}-2$ is colocalized with sGC in olfactory cilia (Ingi and Ronnett, 1995), interest has focused on a potential role of $\mathrm{CO}$ as an endogenous activator of olfactory $\mathrm{sGC}$, thus mediating odor-stimulated cGMP formation (but see Breer et al., 1992). Additional support for $\mathrm{CO}$ came from the finding that ORNs are surprisingly sensitive to $\mathrm{CO}$; submicromolar amounts of $\mathrm{CO}$ are sufficient to regulate the activity of $\mathrm{CNG}$ channels in a cGMP-dependent manner (Leinders-Zufall et al., 1995a). A specific function for CO was suggested by the finding that $\mathrm{CO}$ can mimic the adaptation effect produced by exogenous cGMP (Leinders-Zufall et al., 1996). In the present study, we tested for the involvement of endogenous $\mathrm{CO}$ in olfactory adaptation by examining the effects of pharmacological inhibitors of $\mathrm{CO}$ and NO production. The data clearly reveal that metalloporphyrins with established effects on the release of CO from ORNs (Ingi and Ronnett, 1995) completely abolish LLA, whereas two specific inhibitors of NOS, used at 1000 -fold higher concentrations, are unable to eliminate LLA. The effects of ZnPP-9 cannot 
be explained by its direct actions on sGC because CuPP-9, which is as potent as ZnPP-9 on sGC but does not inhibit heme oxygenase (Yoshinaga et al., 1982; Prabhakar et al., 1995), fails to eliminate LLA. Several other controls rule out that ZnPP-9 influences the cGMP system downstream from HO-2. Therefore, we conclude that LLA is caused by the endogenous release of $\mathrm{CO}$ and subsequent cGMP formation.

Although it remains unclear why ORNs would use a diffusible messenger to produce adaption in the same cell in which the diffusible message is generated, it is likely that $\mathrm{CO}$ has additional functions besides self-adaptation (e.g., in regulating the odor sensitivity of neighboring cells, thus contributing to an effect known as cross-adaptation) (Breer and Shepherd, 1993; LeindersZufall et al., 1995a; Broillet and Firestein, 1996). This could enhance further the spatial contrast of odor signals in the olfactory epithelium. Further support for this notion comes from our result that only those ORNs with heightened sensitivity for cineole exhibit LLA.

\section{How does cGMP formation lead to LLA?}

An important result of the present study is that odor adaptation affects steps in the activation and recovery phase of the cAMPmediated odor response (Fig. 3). This effect is cGMP-dependent because it can be eliminated by selective blockade of the cGMP system (Fig. 4). It is currently not fully understood how cGMP formation leads to odor adaptation. It has been suggested that cGMP acts in ORNs through a cGMP-dependent protein kinase leading to reduced cAMP generation (Kroner et al., 1996). An alternative pathway by which cGMP can influence adaptation is through gating of $\mathrm{CNG}$ channels, resulting in long-lasting $\mathrm{Ca}^{2+}$ entry (Leinders-Zufall et al., 1996). Although the relative contribution of each of these steps to odor adaptation remains to be investigated, it is clear from previous results that cGMP is unable to mediate odor adaptation under conditions in which $\mathrm{Ca}^{2+}$ movements across the cellular membrane are reduced (LeindersZufall et al., 1996). This result argues that cGMP-dependent $\mathrm{Ca}^{2+}$ entry is a critical step in LLA and leads to the proposal that cGMP, through CNG channel activation, initiates $\mathrm{Ca}^{2+}$. dependent feedback regulation of odor transduction; several $\mathrm{Ca}^{2+}$-dependent steps in the cAMP cascade have been described that are consistent with this hypothesis and the kinetic changes of the odor responses identified here (see Discussion in LeindersZufall et al., 1996). The current study provides more evidence for this view demonstrating that odor stimulation results in the generation of two distinct ionic currents, i.e., a transient inward current attributable to activation of the cAMP system (Firestein et al., 1991a) and a persistent inward current of small amplitude, which is denoted background current. Results from several tests (Figs. 2, 5, Table 1) indicate that the background currents are mediated by activation of $\mathrm{CNG}$ channels and depend on the cGMP cascade. Finally, the data indicate that the background currents are causal to LLA because they are always generated before the expression of LLA. Conversely, LLA is absent under conditions in which the generation of the background currents is suppressed.

\section{Functional implications and relevance}

In summary, our results support the concept that cAMP and cGMP signals are active for different periods of time after brief odor stimuli and that cGMP reaches much lower levels in ORNs compared with cAMP. We suggest that these differences provide the physiological basis for different functions in olfactory excita- tion and adaptation. We propose that cAMP and cGMP, at least under the conditions of brief odor stimulation, produce distinctly different $\mathrm{Ca}^{2+}$ signals through $\mathrm{CNG}$ channel activation, being transient in the case of cAMP and more persistent in the case of cGMP. Our preliminary analysis of $\mathrm{Ca}^{2+}$-mediated fluorescence changes in olfactory cilia supports this hypothesis (Zufall et al., 1996). The results should be significant with respect to the recent development that CNG channels are not only expressed in sensory neurons but are also found in many other neurons of the nervous system (Ahmad et al., 1994; Leinders-Zufall et al., 1995b; Kingston et al., 1996). The form of olfactory adaptation identified in this study provides a mechanism that can translate a brief neuronal activation into long-lasting intracellular changes, which determine the odor sensitivity of olfactory neurons for minutes, based on previous exposure to odor ligands. Because there is increasing evidence that slow cGMP second-messenger signals may control the odor sensitivity not only in vertebrates but also in insects (Ziegelberger et al., 1990; Zufall and Hatt, 1991; Boekhoff et al., 1993), long-term adaptation could reflect a general principle of diverse chemosensory systems in dealing with the discontinuous, nonspatial nature of olfactory stimuli.

\section{REFERENCES}

Ahmad I, Leinders-Zufall T, Kocsis JD, Shepherd GM, Zufall F, Barnstable CJ (1994) Retinal ganglion cells express a cGMP-gated cation conductance activatable by nitric oxide donors. Neuron 12:155-165.

Baylin F, Moulton DG (1979) Adaptation and cross-adaptation to odor stimulation of olfactory receptors in the tiger salamander. J Gen Physiol 74:37-55.

Boekhoff I, Seifert E, Göggerle S, Lindemann M, Krüger B-W, Breer H (1993) Pheromone-induced second-messenger signaling in insect antennae. Insect Biochem Mol Biol 23:757-762.

Bredt DS, Snyder SH (1994) Transient nitric oxide synthase neurons in embryonic cerebral cortical plate, sensory ganglia, and olfactory epithelium. Neuron 13:301-313.

Breer H (1993) Second messenger signalling in olfaction. In: The molecular basis of smell and taste transduction, Ciba Foundation Symposium 179, pp 97-114. Chichester, UK: Wiley.

Breer H, Shepherd GM (1993) Implications of the NO/cGMP system for olfaction. Trends Neurosci 16:5-9.

Breer H, Klemm T, Boekhoff I (1992) Nitric oxide mediated formation of cyclic GMP in the olfactory system. NeuroReport 3:1030-1032.

Broillet M-C, Firestein S (1996) Gaseous second messengers in vertebrate olfaction. J Neurobiol 30:49-57.

Brüne B, Ullrich V (1987) Inhibition of platelet aggregation by carbon monoxide is mediated by activation of guanylyl cyclase. Mol Pharmacol 32:497-504.

Brunet LJ, Gold GH, Ngai J (1996) General anosmia caused by a targeted disruption of the mouse olfactory cyclic nucleotide-gated cation channel. Neuron 17:681-693.

Colbert HA, Bargmann CI (1995) Odorant-specific adaptation pathways generate olfactory plasticity in C. elegans. Neuron 14:803-812.

Detwiler PB, Gray-Keller MP (1996) The mechanisms of vertebrate light adaptation: speeded recovery versus slowed activation. Curr Opin Neurobiol 6:440-444.

Dionne V (1994) Emerging complexity of odor transduction. Proc Natl Acad Sci USA 91:6253-6254.

Ekman G, Berglund B, Berglund U, Lindvall T (1967) Perceived intensity of odor as a function of time of adaptation. Scand J Psychol 8:177-186.

Firestein S, Darrow B, Shepherd GM (1991a) Activation of the sensory current in salamander olfactory receptor neurons depends on a G-protein mediated cAMP second messenger system. Neuron 6:825835.

Firestein S, Zufall F, Shepherd GM (1991b) Single odor-sensitive channels in olfactory receptor neurons are also gated by cyclic nucleotides. J Neurosci 11:3565-3572.

Firestein S, Picco C, Menini A (1993) The relation between stimulus and response in olfactory receptor cells of the tiger salamander. J Physiol (Lond) 468:1-10. 
Frings S, Lynch JW, Lindemann B (1992) Properties of cyclic nucleotidegated channels mediating olfactory transduction. J Gen Physiol 100:4567.

Furchgott RF, Jothianandan D (1991) Endothelium-dependent and -independent vasodilation involving cyclic GMP: relaxation induced by nitric oxide, carbon monoxide and light. Blood Vessels 28:52-61.

Getchell TV (1986) Functional properties of vertebrate olfactory receptor neurons. Physiol Rev 66:772-818.

Getchell TV, Shepherd GM (1978) Adaptive properties of olfactory receptors analysed with odour pulses of varying durations. J Physiol (Lond) 282:541-560.

Ignarro LJ, Wood KS, Wolin MS (1984) Regulation of purified soluble guanylate cyclase by porphyrins and metalloporphyrins: a unifying concept. Adv Cyclic Nucleotide Protein Phosphorylation Res 17:267-274.

Ingi T, Ronnett GV (1995) Direct demonstration of a physiological role for carbon monoxide in olfactory receptor neurons. J Neurosci 15:82148222.

Ingi T, Cheng J, Ronnett GV (1996a) Carbon monoxide: an endogenous modulator of the nitric oxide-cyclic GMP signaling system. Neuron 16:835-842.

Ingi T, Chiang G, Ronnett GV (1996b) The regulation of heme turnover and carbon monoxide biosynthesis in cultured primary rat olfactory receptor neurons. J Neurosci 16:5621-5628.

Kharitonov VG, Sharma VS, Pilz RB, Magde D, Koesling D (1995) Basis of guanylate cyclase activation by carbon monoxide. Proc Natl Acad Sci USA 92:2568-2571.

Kingston PA, Zufall F, Barnstable CJ (1996) Rat hippocampal neurons express genes for both rod retinal and olfactory cyclic nucleotide-gated channels: novel targets for cAMP/cGMP function. Proc Natl Acad Sci USA 93:10440-10445.

Kishimoto J, Keverne EB, Hardwick J, Emson PC (1993) Localization of nitric oxide synthase in the mouse olfactory and vomeronasal system: a histochemical, immunological and in situ hybridization study. Eur J Neurosci 5:1684-1694.

Kleene SJ (1994) Inhibition of olfactory cyclic nucleotide-activated current by calmodulin antagonists. Br J Pharmacol 111:469-472.

Kroner C, Boekhoff I, Lohmann SM, Genieser H-G, Breer H (1996) Regulation of olfactory signalling via cGMP-dependent protein kinase. Eur J Biochem 236:632-637.

Kulkarni AP, Getchell TV, Getchell ML (1994) Neuronal nitric oxide synthase is localized in extrinsic nerves regulating perireceptor processes in the chemosensory nasal mucosae of rats and humans. J Comp Neurol 345:125-138.

Kurahashi T, Shibuya $\mathrm{T}$ (1990) $\mathrm{Ca}^{2+}$-dependent adaptive properties in the solitary olfactory receptor cells of the newt. Brain Res 515:261-268.

Lancet D (1986) Vertebrate olfactory reception. Annu Rev Neurosci 9:329-355.

Leinders-Zufall T, Zufall F (1995) Block of cyclic nucleotide-gated channels in salamander olfactory receptor neurons by the guanylyl cyclase inhibitor LY83583. J Neurophysiol 74:2759-2762.

Leinders-Zufall T, Shepherd GM, Zufall F (1995a) Regulation of cyclic nucleotide-gated channels and membrane excitability in olfactory receptor cells by carbon monoxide. J Neurophysiol 74:1498-1508.

Leinders-Zufall T, Rosenboom H, Barnstable CJ, Shepherd GM, Zufall F (1995b) A calcium-permeable cGMP-activated cation conductance in hippocampal neurons. NeuroReport 6:1761-1765.

Leinders-Zufall T, Shepherd GM, Zufall F (1996) Modulation by cyclic GMP of the odor sensitivity of vertebrate olfactory receptor cells. Proc R Soc Lond [Biol] 263:803-811.

Luo D, Vincent SR (1994) Metalloporphyrins inhibit nitric oxidedependent cGMP formation in vivo. Eur J Pharmacol 267:263-267.

Maines MD (1981) Zinc-protoporphyrin is a selective inhibitor of heme oxygenase activity in the neonatal rat. Biochim Biophys Acta 673:339350 .

Maines MD (1993) Carbon monoxide: an emerging regulator of cGMP in the brain. Mol Cell Neurosci 4:389-397.

Marion-Poll F, Tobin TR (1992) Temporal coding of pheromone pulses and trains in Manduca sexta. J Comp Physiol [A] 171:505-512.

Marks GS, Brien JF, Nakatsu K, McLaughlin BE (1991) Does carbon monoxide have a physiological function? Trends Pharmacol Sci 12:185188.
Meffert MK, Haley JE, Schuman EM, Schulman H, Madison DV (1994) Inhibition of hippocampal heme oxygenase, nitric oxide synthase, and long-term potentiation by metalloporphyrins. Neuron 13:1225-1233.

Mori K, Yoshihara Y (1995) Molecular recognition and olfactory processing in the mammalian olfactory system. Prog Neurobiol 45:585-620.

Murphy C (1987) Olfactory psychophysics. In: Neurobiology of taste and smell (Finger TE, Silver WL, eds), pp 251-273. New York: Wiley.

Nakamura T, Gold GH (1987) A cyclic-nucleotide gated conductance in olfactory receptor cilia. Nature 325:442-444.

Nathanson JA, Scavone C, Scanlon C, McKee M (1995) The cellular $\mathrm{Na}^{+}$ pump as a site of action for carbon monoxide and glutamate: a mechanism for long-term modulation of cellular activity. Neuron 14:781-794.

Prabhakar NR, Dinerman JL, Agani FH, Snyder SH (1995) Carbon monoxide: a role in carotid body chemoreception. Proc Natl Acad Sci USA 92:1994-1997.

Reed RR (1992) Signaling pathways in odorant detection. Neuron 8:205209.

Restrepo D, Teeter JH, Schild D (1996) Second messenger signaling in olfactory transduction. J Neurobiol 30:37-48.

Roskams AJ, Bredt DS, Dawson TM, Ronnett GV (1994) Nitric oxide mediates the formation of synaptic connections in developing and regenerating olfactory receptor neurons. Neuron 13:289-299.

Shepherd GM (1994) Discrimination of molecular signals by the olfactory receptor neuron. Neuron 13:771-790.

Stevens CF, Wang Y (1993) Reversal of long-term potentiation by inhibitors of heme oxygenase. Nature 364:147-149.

Verma A, Hirsch DJ, Glatt CE, Ronnett GV, Snyder SH (1993) Carbon monoxide: a putative neural messenger. Science 259:381-384.

Vreman HJ, Gillman MJ, Stevenson DK (1989) In vitro inhibition of adult rat intestinal heme oxygenase by metalloporphyrins. Pediatr Res 26:362-365.

Vreman HJ, Lee OH, Stevenson DK (1991) In vitro and in vivo characteristics of a heme oxygenase inhibitor: ZnBG. Am J Med Sci 302:335341.

Vreman HJ, Ekstrand BC, Stevenson DK (1993) Selection of metalloporphyrin heme oxygenase inhibitors based on potency and photoreactivity. Pediatr Res 33:195-200.

Voigt R, Atema J (1990) Adaptation in chemoreceptor cells. III. Effects of cumulative adaptation. J Comp Physiol [A] 166:865-874.

Yoshinaga T, Sassa A, Kappas A (1982) Purification and properties of bovine spleen heme oxygenase. Amino acid composition and sites of action of inhibitors of heme oxidation. J Biol Chem 257:7778-7785.

Zack-Strausfeld C, Kaissling K-E (1986) Localized adaptation processes in olfactory sensilla of Saturniid moths. Chem Senses 11:499-512.

Zhainazarov AB, Ache BW (1995) Dual second-messenger pathways in olfactory transduction. Curr Opin Neurobiol 5:461-466.

Zhuo M, Scott AS, Kandel RR, Hawkins RD (1993) Nitric oxide and carbon monoxide produce activity-dependent long-term synaptic enhancement in hippocampus. Science 260:1946-1950.

Ziegelberger G, van den Berg MG, Kaissling K-E, Klumpp S, Schultz JE (1990) Cyclic GMP levels and guanylate cyclase activity in pheromonesensitive antennae of the silkmoths Antheraea polyphemus and Bombyx mori. J Neurosci 10:1217-1225.

Zufall F, Firestein S (1993) Divalent cations block the cyclic nucleotidegated channel of olfactory receptor neurons. J Neurophysiol 69:17581768.

Zufall F, Hatt H (1991) Dual activation of a sex pheromone-dependent ion channel from insect olfactory dendrites by protein kinase $\mathrm{C}$ activators and cyclic GMP. Proc Natl Acad Sci USA 88:8520-8524.

Zufall F, Firestein S, Shepherd GM (1991a) Analysis of single cyclic nucleotide gated channels in olfactory receptor cells. J Neurosci 11: 3573-3580.

Zufall F, Shepherd GM, Firestein S (1991b) Inhibition of the olfactory cyclic nucleotide gated ion channel by intracellular calcium. Proc R Soc Lond [Biol] 246:225-230.

Zufall F, Firestein S, Shepherd GM (1994) Cyclic nucleotide gated channels and sensory transduction in olfactory receptor neurons. Annu Rev Biophys Biomol Struct 23:577-607.

Zufall F, Leinders-Zufall T, Rand MN, Shepherd GM, Greer CA (1996) Odor-stimulated calcium signaling in cilia and dendrites of olfactory receptor neurons. Soc Neurosci Abstr 22:259. 